\title{
A METHODOLOGY TO MEASURE SYNERGY AMONG ENERGY-EFFICIENCY PROGRAMS AT THE PROGRAM PARTICIPANT LEVEL
}

Bruce E. Tonn

Carl Wagner

OAK RIDGE NATIONAL LABORATORY 


\section{DOCUMENT AVAILABILITY}

Reports produced after January 1, 1996, are generally available free via the U.S. Department of Energy (DOE) Information Bridge.

Web site http://www.osti.gov/bridge

Reports produced before January 1, 1996, may be purchased by members of the public from the following source.

National Technical Information Service

5285 Port Royal Road

Springfield, VA 22161

Telephone 703-605-6000 (1-800-553-6847)

TDD 703-487-4639

Fax 703-605-6900

E-mail info@ntis.fedworld.gov

Web site http://www.ntis.gov/support/ordernowabout.htm

Reports are available to DOE employees, DOE contractors, Energy Technology Data Exchange (ETDE) representatives, and International Nuclear Information System (INIS) representatives from the following source.

Office of Scientific and Technical Information

P.O. Box 62

Oak Ridge, TN 37831

Telephone 865-576-8401

Fax 865-576-5728

E-mail reports@adonis.osti.gov

Web site http://www.osti.gov/contact.html

This report was prepared as an account of work sponsored by an agency of the United States Government. Neither the United States Government nor any agency thereof, nor any of their employees, makes any warranty, express or implied, or assumes any legal liability or responsibility for the accuracy, completeness, or usefulness of any information, apparatus, product, or process disclosed, or represents that its use would not infringe privately owned rights. Reference herein to any specific commercial product, process, or service by trade name,

trademark, manufacturer, or otherwise, does not necessarily constitute or imply its endorsement, recommendation, or favoring by the United States Government or any agency thereof. The views and opinions of authors expressed herein do not necessarily state or reflect those of the United States Government or any agency thereof and do not necessarily reflect the views of the New York State Energy Research and Development Authority. 
ORNL/CON-491

\title{
A METHODOLOGY TO MEASURE SYNERGY AMONG ENERGY-EFFICIENCY PROGRAMS AT THE PROGRAM PARTICIPANT LEVEL
}

\author{
Bruce E. Tonn \\ Environmental Sciences Division \\ OAK RIDGE NATIONAL LABORATORY \\ Carl Wagner \\ Department of Mathematics \\ UNIVERSITY OF TENNESSEE, KNOXVILLE
}

Date Published: September 2003

Prepared for

New York State Energy Research and Development Authority

Albany, New York

Prepared by

OAK RIDGE NATIONAL LABORATORY

Oak Ridge, Tennessee 37831

managed by

UT-BATTELLE, LLC

for the

U.S. DEPARTMENT OF ENERGY

under contract DE-AC05-00OR22725 


\section{CONTENTS}

Page

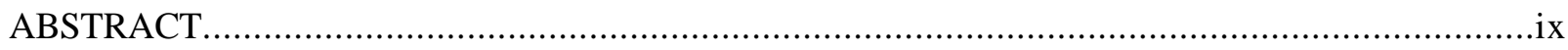

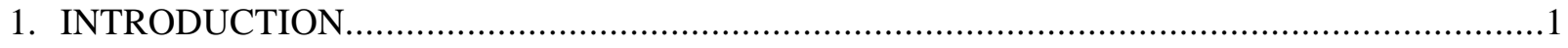

2. CONCEPTUALIZING SYNERGY AT THE PROGRAM PARTICIPANT LEVEL.....................3

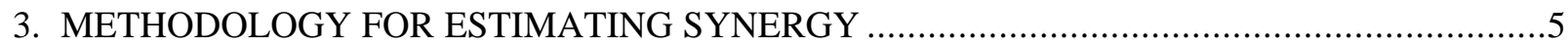

4. MEASURING SYNERGY IN MARKETS WITH MULTIPLE ACTORS ..............................9

5. MEASURING SYNERGY: METHODOLOGICAL REFINEMENTS ...................................13

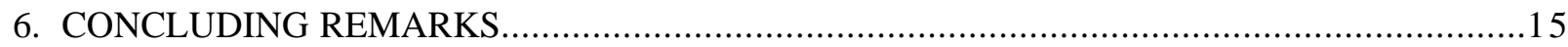

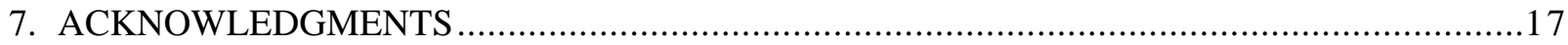

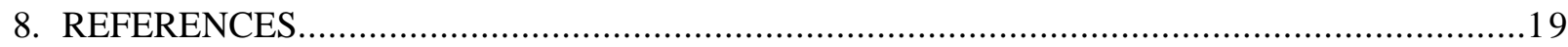




\section{LIST OF FIGURES}

Figure $\quad$ Page

1 Energy-Efficient Motors Market Theory Diagram …...........................................

2 Example Question: New Motor Buyer.....................................................................5

3 Example Question: Motor Vendor ............................................................... 10

$4 \quad$ Example Question: Contractors and Energy Service Companies...............................11 


\section{LIST OF TABLES}

Table

1 Hypothetical Data: Ten New Motor Buyers...
Page

. .7 


\begin{abstract}
This paper presents a methodology designed to measure synergy among energy-efficiency programs at the program participant level (e.g., households, firms). Three different definitions of synergy are provided: strong, moderate, and weak. Data to measure synergy can be collected through simple survey questions. Straightforward mathematical techniques can be used to estimate the three types of synergy and explore relative synergistic impacts of different subsets of programs. Empirical research is needed to test the concepts and methods and to establish quantitative expectations about synergistic relationships among programs. The market for new energy-efficient motors is the context used to illustrate all the concepts and methods in this paper.
\end{abstract}




\section{INTRODUCTION}

This paper presents a methodology designed to measure synergy among energy-efficiency programs at the program participant level. The New York State Energy Research and Development Authority (NYSERDA) offers over thirty-five different energy-efficiency, low-income, and research and development programs. Formally, these programs are designed to: (1) improve system wide energy reliability and peak demand reduction through end user efficiency actions, (2) reduce environmental impacts of energy production and use, (3) facilitate energy competition to benefit end-users, and (4) improve energy efficiency and access to energy options for under-served customers. Fundamentally, these programs are designed to facilitate market development for energyefficient technologies. Simply put, success is measured by having more customers use energy more efficiently.

In many instances, multiple NYSERDA programs have been created that focus on specific types of potential energy-efficient product customers, especially households and commercial businesses. Figure 1 presents one such example, where multiple NYSERDA programs have the potential for influencing the purchase of energy-efficient motors by firms. Some of the programs provide direct financial incentives, such as the Smart Equipment Choices Program, whereas others provide only information on energy-efficiency, such as the ENERGY STAR ${ }^{\circledR}$ Public Awareness Campaign. The question addressed by this research is whether the combined influences of multiple programs on customer energy-efficiency decision making is simply the sum of their parts or something greater. 'Synergy' is the term used here to connote something greater. The greater the synergy among programs, the greater the overall effectiveness of NYSERDA's portfolio of programs.

Other research supported by NYSERDA has conceptualized synergy in other ways. For example, synergy can be assessed from a programmatic process perspective: Have NYSERDA program managers designed programs to meet certain conditions that would indicate the intentional creation of synergies among programs? Additionally, synergy among programs could be conceptualized as the acceleration of the market penetration of new technologies not only faster than the typical time it takes for new technologies to replace old technologies without any government intervention, but also faster than the typical time with the benefit of "non-synergistic" government or other program intervention. Synergy can also be hypothesized to increase the ultimate level of market penetration of new energy efficient technologies. (DeCotis et al. 2002)

This research offers a third perspective on synergy, as measured at the level of market actors, such as purchasers and sellers of energy-efficient products. For example, do potential purchasers of energy-efficient products, such as firms in the market for new motors, act in ways that indicate that synergies exist among the various NYSERDA programs available to them? While it is not possible to measure the actual cognitive processes in the minds of such decision makers, it is possible to collect data through a simple survey approach and process the data using well-known mathematical techniques to estimate through the behavior of program participants synergies exhibited by NYSERDA programs.

The next section of this paper presents the general approach developed by Oak Ridge National Laboratory (ORNL) to conceptualize synergy in this third manner. Section 3 presents the survey methodology and mathematical techniques that can be used to measure synergy. Section 4 discusses how the methodology can be extended to measure synergies up-stream of energyefficiency end-use customers. Section 5 presents several methods that can be used to explore the synergistic impacts of individual programs and subsets of programs. 


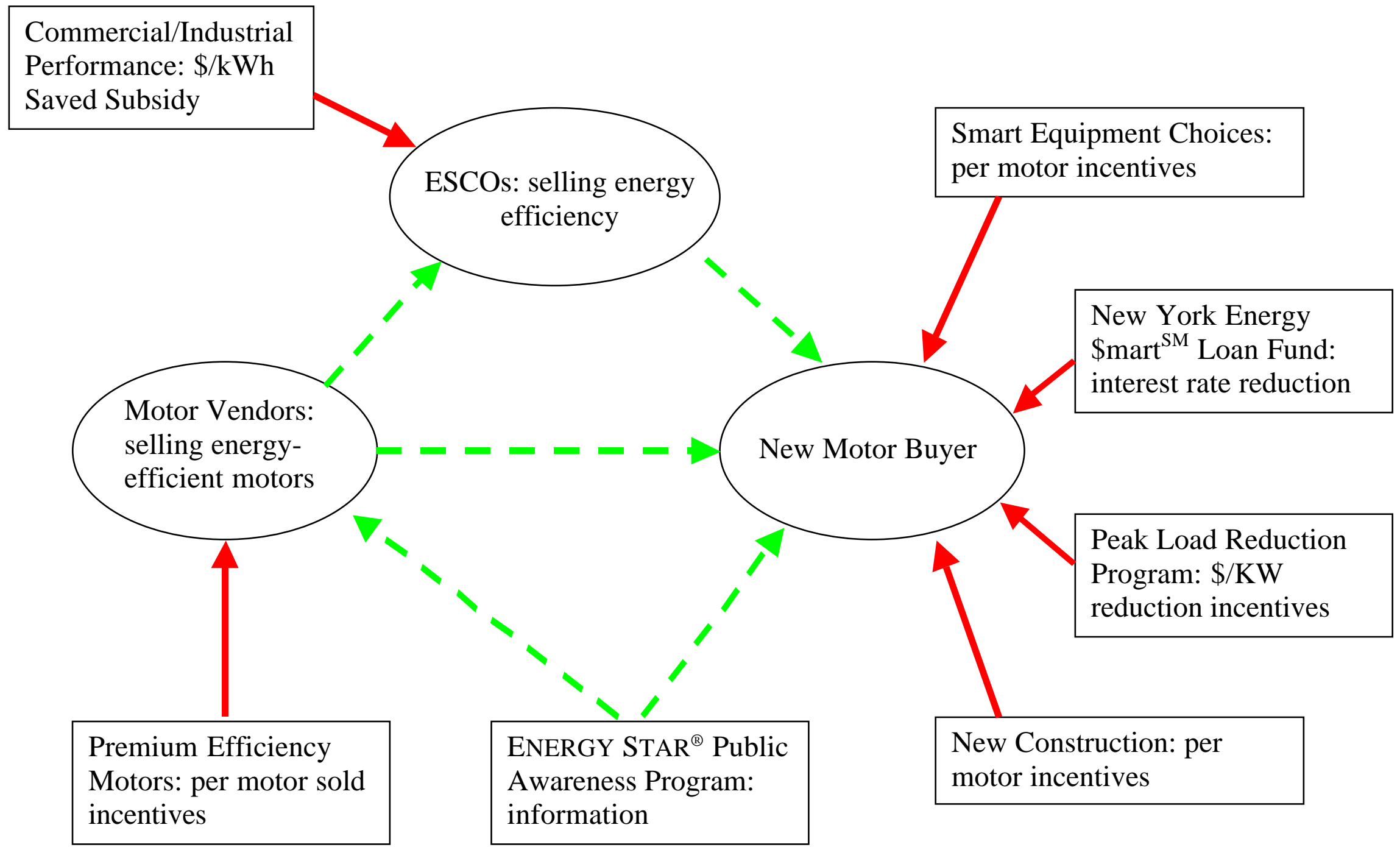

LEGEND: $>$ Financial Subsidy/Benefit $->$ Information/Marketing

Figure 1. Energy-Efficient Motors Market Theory Diagram. 


\section{CONCEPTUALIZING SYNERGY AT THE PROGRAM PARTICIPANT LEVEL}

As discussed in DeCotis et al. (2002), one pre-condition for creating programmatic synergies is the implementation of a portfolio of programs. The assumption is that the portfolio of programs will have a more substantial impact on market transformation than would single programs. As illustrated in Figure 1, NYSERDA has implemented a portfolio of programs to transform the market for energy-efficient motors. The programs are designed to influence many different types of actors (represented by circles), including new motor buyers (typically firms), motor vendors, and contractors, and energy service companies (ESCOs). Seven NYSERDA programs (represented by rectangles) provide a combination of financial subsidies and benefits and information to these market actors with the goal of positively influencing the purchase of new, premium efficiency motors.

Let's first focus on new motor buyers. Figure 1 indicates that there are at least seven sources of influence upon these market actors. There are four NYSERDA financial subsidy and benefit programs that could directly influence these actors: Smart Equipment Choices, New York Energy \$mart ${ }^{\text {SM }}$ Loan Fund, Peak Load Reduction Program and New Construction Program. One NYSERDA information program can directly impact these actors, the ENERGY STAR ${ }^{\circledR}$ Public Awareness Program. Lastly, it can be assumed that new motor buyers receive information about the benefits of energy-efficient motors from both motor vendors, and contractors and ESCOs, which receive financial subsidies from two other NYSERDA programs to specifically sell new energy-efficient motors and more generally promote energy-efficiency, respectively. Thus, motor vendors, and contractors and ESCOs should be identified as NYSERDA-related sources of influence upon new motor buyers.

Now let's systematically construct definitions of synergy for an entire portfolio of programs that could influence a prospective energy-efficient motor buyer. First, let's define three cases where synergy can be assumed not to exist. One, no synergy among the programs can be said to exist if a new motor buyer opted not to purchase any energy-efficient motors. Two, no synergy can be said to exist if a new motor buyer actually purchases one or more energy-efficient motors but reports that none of the seven sources of influence depicted in Figure 1 had any influence on the decision to purchase the motors. Third, no synergy can be said to exist if one and only one program had any influence on the purchase of an energy-efficient product. This is because synergy, by definition, requires the interaction of two or more programs.

Now let's take a more positive approach and define synergy in the strongest possible fashion, which is simply labeled strong synergy. Strong synergy can be said to exist if a new motor buyer reports that the purchase of one or more energy-efficient motors absolutely would not have been made without the financial subsidies, benefits or information provided by two or more NYSERDArelated sources of influence in combination. The assumption here is that if any of the programs that provided the influence had not been in existence, the decision to purchase an energy-efficient motor would not have been made. The further assumption is that there is something fundamental about the interaction among those two or more programs as experienced by the new motor buyer that was necessary for the decision to be made. One can interpret this interaction as the strongest, most defensible (but most limited) conceptualization of synergy at the level of program participants that can be offered.

At least two other definitions of synergy can be offered, both less rigorous than strong synergy. Moderate synergy can be said to exist if the new motor buyer reports that the purchase of one or more energy-efficient motors was at least moderately influenced by two or more NYSERDArelated sources of influence. Weak synergy can be said to exist if the new motor buyer reports that the purchase of one or more energy-efficient motors was at least weakly influenced by two or more NYSERDA-related sources of influence. 
With respect to moderate and weak synergy, the new motor buyer does not make any claims that the existence of two or more NYSERDA-related programs were absolutely necessary for the decision to purchase energy-efficient motors. Instead, it is assumed that the existence of the programs, when combined with each other, exerted at least enough influence to push the decision toward the purchase of energy-efficient motors and away from standard motors. An analogy can be made to a court of law, where juries and judges weigh various pieces of evidence to determine innocence or guilt. When a preponderance of evidence exists and the pieces of evidence fit together in a logical fashion, a defendant can be judged guilty even if no one piece of evidence absolutely proves the guilt of the defendant. In our case, influences of various programs upon decisions of prospective purchasers of energy-efficient products are analogous to pieces of evidence in court of law. To establish the existence of synergy, the influences (or pieces of evidence) must be stronger in the moderate synergy case than in the weak synergy case.

Why provide three definitions of synergy at the program participant level? The main reason is that no empirical work has been done to suggest how much synergy can be expected to exist among sources of influence. It could be that the definition of strong synergy is overly restrictive, that no participants would report that two or more sources of influence were absolutely necessary to make a positive energy-efficiency purchase decision. On the other hand, it could be that every participant could report some level of weak synergy, in which the weak definition of synergy would lose some of its ability to provide insightful information about synergy. Several empirical studies will help to shape our expectations about synergy. It can also be expected that these studies would even lead to improved definitions of the concept of synergy at the participant level.

As a final point, these definitions of synergy can be interpreted as being 'direct' rather than 'indirect' conceptualizations. In other words, the influences incorporated in the definitions and illustrated in Figure 1 all exist within a well-defined market area, such as new motors. However, it could be that there are 'spillover' effects from programs and energy-efficient product purchases in other markets upon decisions to purchase new, energy-efficient motors. For example, prior decisions to purchase energy-efficient lighting, which could have been spurred by NYSERDA-related influences, could potentially foster an 'efficiency ethic' that could have strongly influenced the purchase of new, energy-efficient motors. Without doubt, indirect synergistic effects should be addressed but it is recommended that this challenge be reserved for the next phase of this aspect of research on synergy. 


\section{METHODOLOGY FOR ESTIMATING SYNERGY}

This section discusses how simple survey questions and straightforward mathematical techniques can be used to estimate synergy among programmatic sources of influence at the level of program participants.

Figure 2 illustrates a simple survey question that can be used to collect data to measure synergy. It is assumed that the survey respondent has recently purchased an energy-efficient motor. As discussed above and illustrated in Figure 1, this customer could have been influenced by several NYSERDA-related programs. Four programs could have provided direct financial subsidies and benefits to the new motor buyer (e.g., Smart Equipment Choices, New York Energy \$mart ${ }^{\text {SM }}$ Loan Fund). Several NYSERDA programs, such as the ENERGY STAR ${ }^{\circledR}$ Public Awareness Campaign, could have indirectly provided information about energy-efficiency to the decision maker. Additionally, NYSERDA incentives provided to contractors and ESCOs to sell energy-efficiency products and services to firms that buy motors could have spurred these market actors to provide their prospective customers with energy-efficiency information. The ultimate customers may also have received information from motor vendors, who also receive incentives from NYSERDA to sell premium efficiency motors. Thus, the example question lists all seven potential NYSERDA sources of influence on the new motor buyer's decision-making. The respondent is simply asked to indicate how influential each source was on their decision, using a Likert Scale from 0 to 3, where 0 represents no influence, 1 - weak influence, 2 - moderate influence, and 3 - strong or absolute influence.

Please rate the influence of each NYSERDA program and NYSERDA-related source of information on your energy-efficient motor(s) purchase. (Please circle appropriate answer)

\begin{tabular}{|c|c|c|c|c|c|}
\hline & $\begin{array}{l}\text { No } \\
\text { Influence }\end{array}$ & $\begin{array}{l}\text { Weak } \\
\text { Influence }\end{array}$ & ${ }_{\text {Influence }}^{\text {Moderate }}$ & Stror & ence* \\
\hline & & & & & N/A \\
\hline Smart Equipment Choices & 0 & 1 & 2 & 3 & 99 \\
\hline $\begin{array}{l}\text { New York Energy } \$ \text { mart }^{\mathrm{SM}} \\
\text { Loan Fund }\end{array}$ & 0 & 1 & 2 & 3 & 99 \\
\hline Peak Load Reduction Program & 0 & 1 & 2 & 3 & 99 \\
\hline New Construction Program & 0 & 1 & 2 & 3 & 99 \\
\hline Motor Vendor & 0 & 1 & 2 & 3 & 99 \\
\hline $\begin{array}{l}\text { Contractor or } \\
\text { Energy Service Company }\end{array}$ & 0 & 1 & 2 & 3 & 99 \\
\hline $\begin{array}{l}\text { ENERGY STAR }^{\circledR} \text { Public } \\
\text { Awareness Campaign }\end{array}$ & 0 & 1 & 2 & 3 & 99 \\
\hline
\end{tabular}

Figure 2. Example Question: New Motor Buyer. 
From the viewpoint of a new motor buyer, the three different types of synergy for an entire portfolio of programs can be defined in these ways:

$>$ strong synergy is said to exist if two or more of these sources of influence were rated as strong or absolute (i.e., given the score of 3 );

$>$ moderate synergy is said to exist if two or more sources of influence received ratings of 2 or higher; and

weak synergy is said to exist if two or more sources of influence received ratings of 1 or higher.

As noted above, moderate synergy subsumes strong synergy and weak synergy subsumes both strong and moderate synergy. In other words, the magnitude of moderate synergy will always be equal to or greater than strong synergy and the magnitude of weak synergy will always be equal to or greater than moderate synergy. No synergy can be said to exist if (1) all the sources of influence had ratings of 0 , or (2) if only one source of influence had a rating greater than 0 .

Let's assume that ten energy-efficient motor buyers answered this question and provided the hypothetical ratings in Table 1 . Column 2 indicates the number of energy-efficient motors bought by each respondent, which total to forty for this sample. Column 3 indicates the fraction of energyefficient motors bought by each respondent. For example, respondent \#2 bought two motors, which represents $5 \%$ of the total number of energy-efficient motors purchased by this sample of respondents. The remaining columns contain the ratings provided by each respondent for each of the seven NYSERDA sources of influence contained in the question in Figure 2.

Strong synergy for an entire portfolio of programs influencing a new motor buyer can be estimated by the sum of the fraction of motors bought whose respondents reported experiencing strong synergy (i.e., reported two or more sources of influence as having ratings of 3). Given this definition, the magnitude of synergy can range from 0.0 (no strong synergy) to 1.0 (total or complete strong synergy). In this hypothetical data set, five respondents met this criterion for strong synergy (respondents 2, 3, 6, 8 and 10). For example, respondent \#6 indicated that the Smart Equipment and the New York Energy \$mart ${ }^{\mathrm{SM}}$ Loan Fund Programs were absolutely necessary in his or her decision to buy ten energy-efficient motors. The sum of the fraction of motors purchased by these five respondents is 0.60 . Thus, in this case, the magnitude of strong synergy among all these sources of influence is estimated to be 0.60 , out of a maximum value of 1.00 .

To continue, moderate synergy can be estimated by the sum of the fraction of motors bought whose respondents reported experiencing moderate synergy (i.e., reported two or more sources of influence as having ratings of 2 or greater). Seven respondents met this criterion, the five respondents who met the strong synergy criterion and two others, respondents 1 and 4 . The sum of the fraction of motors purchased by these seven respondents is 0.775 . In other words, moderate synergy is estimated to be 0.775 out of a maximum value of 1.00 .

Lastly, weak synergy can be estimated by the sum of the fraction of motors bought whose respondents reported experiencing weak synergy (i.e., reported two or more sources of influence as having ratings of 1 or greater). Eight respondents met this criterion, the seven who met the moderate synergy criterion and one other respondent, \#9. The estimated value of weak synergy is 0.925 out of a maximum of 1.00. Only two respondents, \#5 and \#7, reported no synergy; in fact they reported no influences from NYSERDA programs upon their purchase decisions.

To reiterate a point made in the previous section, several empirical studies are required before expectations about the estimates of synergy can be developed. It is not known whether 0.60 is an appropriate level of strong synergy, or extraordinarily high or low. The same can be said for the estimates of moderate and weak synergy. Thus, the estimates generated by this hypothetical example should not be used as benchmarks when assessing relative synergistic successes or failures among programs. 
Table 1. Hypothetical Data: Ten New Motor Buyers

\begin{tabular}{|c|c|c|l|l|l|l|l|c|c|}
\hline $\begin{array}{l}\text { Motor } \\
\text { Buyer }\end{array}$ & $\begin{array}{l}\text { \# EE } \\
\text { Motors } \\
\text { Bought }\end{array}$ & $\begin{array}{l}\text { Fraction } \\
\text { of EE } \\
\text { Motors } \\
\text { Bought }\end{array}$ & $\begin{array}{l}\text { Smart } \\
\text { Equip. }\end{array}$ & $\begin{array}{l}\text { Loan } \\
\text { Fund }\end{array}$ & $\begin{array}{l}\text { Peak } \\
\text { Load }\end{array}$ & $\begin{array}{l}\text { New } \\
\text { Constr. }\end{array}$ & $\begin{array}{l}\text { ESCO } \\
\text { info }\end{array}$ & $\begin{array}{l}\text { Motor } \\
\text { Vendor } \\
\text { Info }\end{array}$ & $\begin{array}{l}\text { Energy } \\
\text { Star } \\
\text { Info }\end{array}$ \\
\hline 1 & 5 & .125 & 0 & 3 & 0 & 0 & 1 & 2 & 1 \\
\hline 2 & 2 & .05 & 0 & 0 & 3 & 3 & 2 & 2 & 2 \\
\hline 3 & 6 & .15 & 0 & 1 & 0 & 3 & 3 & 3 & 2 \\
\hline 4 & 2 & .05 & 3 & 0 & 0 & 0 & 1 & 2 & 2 \\
\hline 5 & 1 & .025 & 0 & 0 & 0 & 0 & 0 & 0 & 0 \\
\hline 6 & 10 & .25 & 3 & 3 & 0 & 0 & 1 & 1 & 1 \\
\hline 7 & 2 & .05 & 0 & 0 & 0 & 0 & 0 & 0 & 0 \\
\hline 8 & 4 & .10 & 0 & 0 & 0 & 0 & 3 & 3 & 3 \\
\hline 9 & 6 & .15 & 0 & 0 & 0 & 0 & 0 & 1 & 3 \\
\hline 10 & 2 & .05 & 3 & 3 & 0 & 0 & 0 & 1 & 1 \\
\hline Sum & 40 & 1.00 & & & & & & & \\
\hline
\end{tabular}




\section{MEASURING SYNERGY IN MARKETS WITH MULTIPLE ACTORS}

The previous section focused on estimating synergy for one actor in one market, new motor buyers in the new motor market. At least seven NYSERDA-related sources of influence could affect the decision to purchase energy-efficient motors by these market actors. However, as illustrated in Figure 1, there are two other groups of actors in the new motor market that have not been addressed; new motor vendors, and contractors and ESCOs. The question addressed in this section is how to estimate synergy among programs in markets with multiple actors.

The basic answer to this question is that synergy at the participant level can only be measured with respect to one group of participants at a time. Thus, with respect to the new motor market, synergy can only be measured separately for each group of actors in this market, such as new motor buyers, motor vendors, and contractors and ESCOs. A method of estimating synergy for new motor buyers was described above. To estimate the synergistic effects of NYSERDA-related influences upon motor vendors and ESCOs, the methodology would need to be replicated in each case.

For example, motor vendors would need to be surveyed separately, using the question contained in Figure 3. This question also contains seven NYSERDA-related sources of influence. As is depicted in the new motors market theory diagram in Figure 1, there are two sources of influence on new motor vendors: the Premium Efficiency Motors Program, which provides incentives directly to motor vendors, and the ENERGY STAR ${ }^{\circledR}$ Public Awareness Campaign, which indirectly influences motor vendors through more broadly disseminated information. However, it can also be hypothesized that new motor vendors carry energy-efficient motors because they are demanded by new motor buyers (and of course, these buyers are influenced by various NYSERDA programs). Additionally, new motor vendors may carry energy-efficient motors because they know that the existence of NYSERDA programs designed to influence new motor buyers has or will transform the market for new motors. Thus, these four programs could also be influencing new motor vendors: Smart Equipment Choices, New York Energy \$mart ${ }^{\text {SM }}$ Loan Fund, Peak Load Reduction, and New Construction.

A completely similar explanation is offered for the seven influences contained in the question for contractors and ESCOs, as shown in the question in Figure 4. As in the case with new motor vendors, there are only two direct NYSERDA-related sources of influence upon contractors and ESCOs, the Commercial/Industrial Performance Program and motor vendors who may be pushing contractors and ESCOs to buy their energy-efficient motors. Additionally, new motor buyers and the existence of the four programs noted above may also be influencing contractors and ESCOs. The mathematics as described above can be used to estimate the three types of synergy from the viewpoint of these other market actors.

It should be noted that estimates of synergy determined with respect to one market actor cannot be shifted or assigned to other market actors. For example, it might be tempting to attribute estimates of synergy to the Premium-Efficiency Motors Program in the case of new motor buyers because motor vendors influence new motor buyers and this program influences motor vendors. Such attribution shifting is not recommended primarily because the second market actor in question, in this case the new motor buyer, was not as directly influenced by the program as was the motor vendor. In fact, it is not the Premium-Efficiency Motors Program that influences the end-user, it is the extra 'push' the vendor gives to make the sale. In some cases, the new motor buyer may no knowledge of the mid-stream focused program. In these cases, without explicit knowledge the program, by definition, there cannot be any synergy attributed to that progrom at the level of a program participant. In a similar way, the Commercial/Industrial Performance Program cannot be said to have had any synergistic influence upon the decisions of new motor buyers.

However, the point needs to be made that this paper is focusing only on synergy. The methods presented in this paper cannot be used to allocate overall attribution of each NYSERDA program to the purchase of energy-efficient motors. For example, it could be that the Smart 
Equipment Choices Program is a key contributor to synergy among programs as exhibited by the new motor buyers but that the Premium Efficiency Motors Program has the most influence upon the transformation of the new motors market. The methods developed herein could support the first contention but not the second. Different methods are needed to explore the second contention and should be considered in future research.

Please rate the influence of each NYSERDA program on your decision to actively market energyefficient motors. (Please circle appropriate answer)

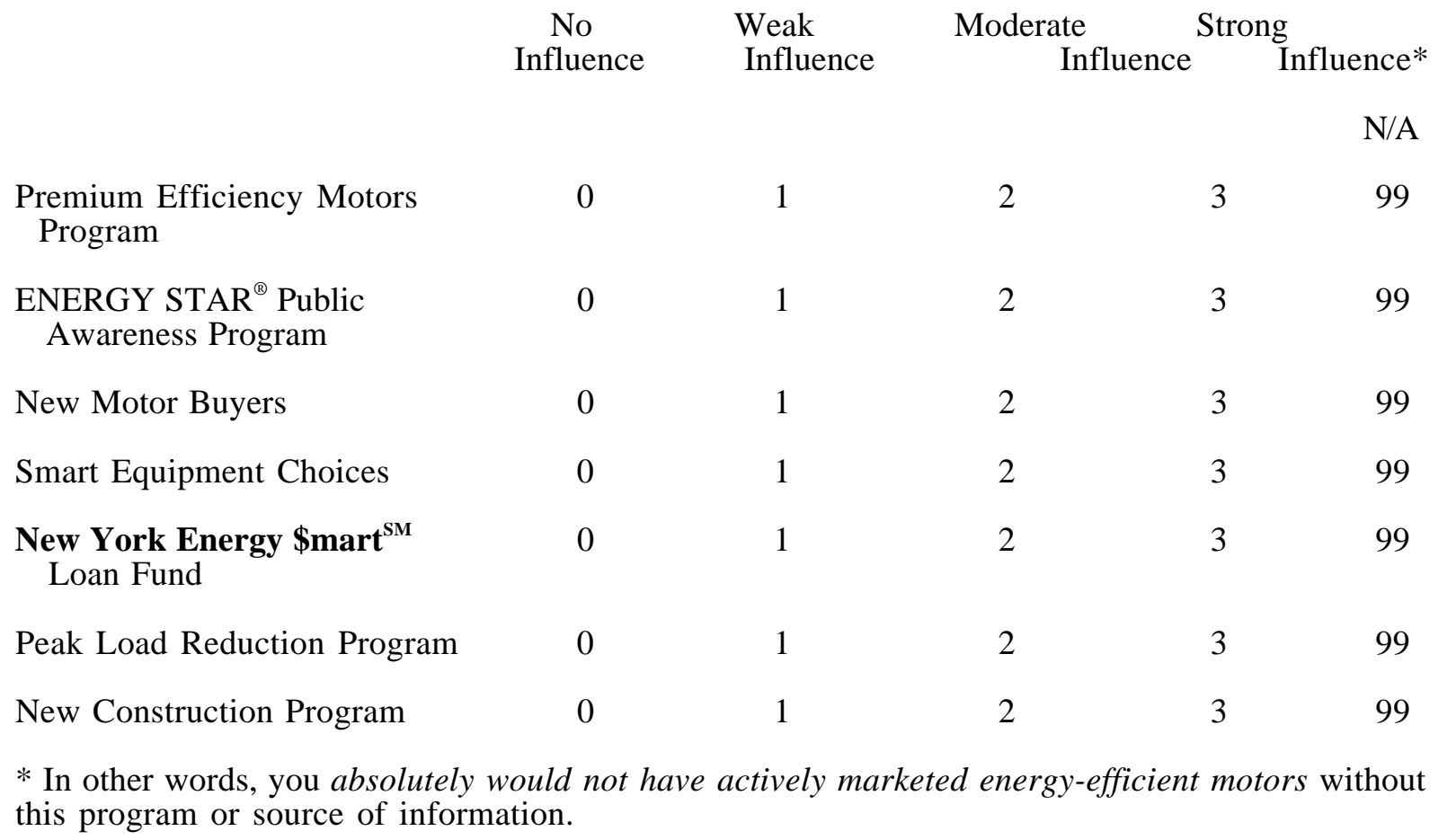

Figure 3. Example Question: Motor Vendor. 
Please rate the influence of each NYSERDA program and NYSERDA-related source of information on your decision to actively market energy-efficient motors. (Please circle appropriate answer)

$\begin{array}{cl}\text { No } & \text { Weak } \\ \text { Influence } & \text { Influence }\end{array}$

Commercial/Industrial

Performance Program

Motor Vendors

New Motor Buyers

Smart Equipment Choices

New York Energy $\$$ mart $^{\text {sM }}$

Loan Fund

Peak Load Reduction Program

New Construction Program
0

0

0

0

0

0

0
Moderate Influence Influence*

N/A

99

99

$12 \quad 3 \quad 99$

12

$3 \quad 99$

1

2

3

99

(20)

12

3

1

3

99

* In other words, you absolutely would not have actively marketed energy-efficient motors without this program or source of information.

Figure 4. Example Question: Contractors and Energy Service Companies. 


\section{MEASURING SYNERGY：METHODOLOGICAL REFINEMENTS}

It is likely that program managers will have many additional questions about synergy. Thus far, the only question answered is how to estimate the synergy among the entire portfolio of NYSERDA-related programs and the influence of sources of information upon a market actor, such as a new motor buyer. This section describes how the basic methodology can be refined to answer other questions.

One question might be: How much synergy might be lost if a program were eliminated? For example, and only for the sake of discussion, let's assume that the Smart Equipment Choices Program was eliminated. What would be the impact upon synergy from the viewpoint of new motor buyers? First, let's examine the impact upon strong synergy. The contributions to synergy for each respondent who indicated that this program was absolutely necessary to his or her decision to purchase energy-efficient new motors (i.e., who gave that program rating of 3) would need to be subtracted from the overall estimate of strong synergy. Using Table 1 as an example, the Smart Equipment Choices Program contributed to strong synergy in two cases, as reported by respondents 6 and 10. The portfolio-wide estimate of strong synergy would need to be reduced by 0.25 and 0.05 , respectively. Thus, overall strong synergy would be reduced from 0.60 to 0.30 , or by $50 \%$. In this hypothetical case, this program could be judged to be a significant contributor to strong synergy.

Unfortunately, less can be said about the impact of dropping programs within the contexts of moderate and weak synergy. Unlike in the strong synergy case, dropping a program in these contexts might not have eliminated the possibility of the purchase of energy-efficient motors. The synergistic effects among the remaining programs could have been sufficient to support such a purchase. However, this is only the case where there are three or more programs contributing to synergy in the moderate and weak contexts. If there are only two programs contributing to synergy, then removing one will eliminate the synergy experienced by that new motor buyer. So, let's consider the impact upon moderate synergy of the elimination of the Smart Equipment Choices Program. Other than respondents 6 and 10, the only other respondent indicating that that program had any influence upon new motor decisions was respondent \#4, which gave the program a rating of 3. However, the respondent also gave ratings of 2 to two other sources of information, motor vendors and the ENERGY STAR ${ }^{\circledR}$ Public Awareness Campaign. Thus, moderate synergy would not be reduced by more than the 0.30 indicated above. However if the New York Energy \$mart ${ }^{\mathrm{SM}}$ Loan Fund Program was eliminated, the contributions to synergy would be lost from respondents 6 and 10 (because of the loss of strong synergy) and from respondent \#1, because this program has a moderate synergistic relationship with the motor vendor source of information. Thus, the reduction in moderate synergy in this case would be from 0.775 to 0.350 .

It should be noted that the impact of eliminating a program upon synergy is different from the impact of eliminating a program upon sales. It can be assumed that all sales to respondents would be lost from all eliminated programs for which respondents gave a rating of 3 . This is because these programs, whether they interacted with any other programs in synergistic manners, were absolutely necessary for the purchase to have been made. So, for example, the elimination of the Smart Equipment Choices program would have resulted in the loss of $35 \%$ of the sales of energy-efficient motors for this set of hypothetical respondents who were influenced by NYSERDA programs (i.e., respondents 4, 6 and 10 would not have bought energy-efficient motors). Nothing can be said with certainty about the impact upon sales of eliminated programs that had ratings of only $1 \mathrm{~s}$ and $2 \mathrm{~s}$.

The last topic addressed in this section is relative synergy. Can something be said about the relative synergy of subsets of programs that could influence market actors in addition to estimating synergy among the entire portfolio of programs? The answer is yes but only in limited cases and in limited ways. The basic approach is that the synergy attributable to a subset of programs is the sum of synergy attributable to that subset plus all its subsets with 2 or more elements. The ratings of all other sources of influence are ignored for these calculations. However, if any sources of influence outside of the subset received non-zero ratings, then the synergy for that respondent cannot be attributed nor even partially allocated to the subset. 
First let's examine strong synergy that could be associated with three NYSERDA-related sources of information, contractors and ESCOs, motor vendors, and ENERGY STAR ${ }^{\circledR}$ Public Awareness Campaign. These are the last three programs listed in Table 1. Most straight-forwardly, the synergy associated with respondent \#8 can be associated with this subset, as the only three influences reported by that respondent are these three and the respondent gave all influences a rating of 3 . Thus, synergy of at least 0.10 can be attributed to this subset.

It turns out that this is all that can be attributed to this subset. Reviewing respondent \#3 for instance, a program not in the subset received a rating of three. Because of this, strong synergy associated with respondent \#3 cannot be solely attributed to the subset and it does not appear possible to allocate synergy among all those programs in a strong synergistic relationship. So, synergy associated with respondent \#3 cannot be attributed to our example subset. On the other hand, if respondent \#3's rating for the New Construction Program had been a two or lower, then that amount of synergy could have been attributed to our example subset because synergy of subsets of the subset under examination can be counted. In this case, ESCO information and motor vendor information represent a subset of the larger subset and both and only both received a rating of 3 .

Now let's examine weak synergy associated with these three programs. As before, synergy associated with respondent \#8 can be counted toward weak synergy for this subset. The only other respondent who only reported ratings for this subset is respondent \#9, who gave a rating of 1 to the motor vendor source of influence and a rating of 3 to the ENERGY STAR ${ }^{\circledR}$ Public Awareness Program. Since these two programs are a subset of our example subset, the synergy attributable to this respondent can be counted. Thus, the total weak synergy directly attributable to the subset of three programs is 0.25 . Given that these three programs also had synergistic influences on six other respondents, the method just outlined should be considered a lower bound for estimating the synergistic influences of subsets of programs. 


\section{CONCLUDING REMARKS}

This paper presents definitions of synergy among a portfolio of programs at the level of program participants. Three definitions were presented, for strong, moderate, and weak synergy. Strong synergy is the most rigorous and theoretically defensible definition of synergy. However, cases can be made for estimating moderate and weak synergy, too. Several empirical studies are needed to test the concepts, questions, and estimation techniques. These studies would also begin to help shape expectations for magnitudes of synergy among programs in different market contexts. It can be expected that the empirical studies will help to improve and refine the methodology presented above. Empirical studies focusing on the markets for energy-efficient motors and lighting products would be good starting points.

It should be noted that this methodology focuses solely on the issue of synergy. It also focuses only on 'direct synergy'; future research should address the assessment of 'indirect synergy.' It cannot be used to allocate overall influence of various NYSERDA programs upon the transformation of markets for energy efficient products. It may be possible that the information collected by questions such as those contained in Figures 2 through 4 could be used as the basis for an additional methodology to allocate attribution among programs. It could be expected that the synergy methodology would need to be incorporated in this new methodology. Other factors might also be considered, such as how much money is being spent on each program and influences beyond NYSERDA programs, such as changes in energy prices and changes in attitudes about energy use. 


\section{ACKNOWLEDGMENTS}

We thank Jennifer Ellefsen, Larry Pakenas, Helen Kim, Ruth Horton, Paul DeCotis, Linda Berry, and Marty Schweitzer for their comments on this paper. 


\section{REFERENCES}

DeCotis, P., Tonn, B., Pakenas, L, and Eisenberg, J. 2002. "Systems-Based Portfolio Evaluation: Diagnostic Benefits and Methodological Challanges," ACEEE 2002 Conference Proceedings, August. 
INTERNAL DISTRIBUTION

$\begin{aligned} \text { 1. } & \text { L. G. Berry } \\ \text { 2. } & \text { M. A. Brown } \\ \text { 3. } & \text { T. R. Curlee } \\ \text { 4. } & \text { J. E. Christian } \\ \text { 5. } & \text { W. G. Craddick } \\ \text { 6-30. } & \text { M. T. Eady } \\ \text { 31. } & \text { J. F. Eisenberg } \\ \text { 32. } & \text { E. C. Fox } \\ \text { 33. } & \text { M. B. Gettings }\end{aligned}$

34. S. G Hildebrand

35. R. M. Lee

36. M. Martin

37. M. Schweitzer

38. R. L. Schmoyer

39-41. B. E. Tonn

42-44. ESD Library

45. ORNL Center Research Library

46. ORNL Laboratory Records-RC

\section{EXTERNAL DISTRIBUTION}

47. Les Baxter, Pew Charitable Trusts, 2005 Market Street, Suite 1700, Philadelphia, PA 19103

48. Jeff Dowd, U.S. Department of Energy, 1000 Independence Avenue, S.W., EE-3B, Washington, DC 20585

49-52. Jennifer Ellefsen, Project Manager, Energy Analysis, NYSERDA, 17 Columbia Circle, Albany, NY 12203-6399

53. Marvin Horowitz, Demand Research, 3311 Prince William Drive, Fairfax, VA 22031

54. Nick Hall, TecMarket Works, 165 W. Netherwood, Suite A, $2^{\text {nd }}$ Floor, Oregon, WI 53575

55. Ken Keating, Bonneville Power Administation, 905 NE $11^{\text {th }}$ Avenue, MS PNG-1, P.O. Box 3621, Portland, OR 97232

56. Douglas Mahone, Heschong Mahone Group, 11626 Fair Oaks Boulevard, Suite 302, Fair Oaks, CA 95628

57. H. Gil Peach, H. Gil Peach \& Associates, 16232 N.W. Oak Hills Drive, Beaverton, OR 97006-5242

58. Lori Megdal, Megdal \& Associates, 198 High Street, Acton, MA 01720-4218

59. Jane Peters, Research Into Action, P.O. Box 12312, Portland, OR 97212

60. John Reed, Innovologie, 305 Summer Garden Way, Rockville, MD 20850

61. Lisa Skumatz, Skumatz Economic Research Associates, 762 Eldorado Drive, Superior, CO 80027

62. Bill Saxonis, New York Department of Public Services, 3 Empire State Plaza, $8^{\text {th }}$ Floor, Albany, NY 12223

63. Dan Violette, Summit Blue Consulting, $172214^{\text {th }}$ Street, Suite 230, Boulder, CO 80302 